\title{
Variação geossocial do item lexical riacho/córrego nas capitais brasileiras
}

\author{
Abdelhak Razky \\ Romário Duarte Sanches ${ }^{b}$
}

\begin{abstract}
Resumo
Pretende-se, neste trabalho, analisar e cartografar a variação lexical do item riacho/córrego do ponto de vista da dialetologia pluridimensional (THUN, 2000), integrando-o assim ao quadro metodológico da geossociolinguística (RAZKY, 2004; 2013). Os dados analisados aqui, sob a perspectiva geossocial, compõem o banco de conhecimento sobre o português brasileiro do projeto nacional Atlas Linguístico do Brasil - ALiB. A extração de dados lexicais segue um protocolo metodológico homogêneo que caracteriza o corpus do ALiB. Trata-se da pergunta de número 001, do Questionário Semântico-Lexical (QSL). A análise exploratória contempla um número total de 200 informantes, distribuídos pelas 25 capitais brasileiras, tendo por base a seleção dos informantes por estratificação social (idade, sexo e escolaridade), proposta pelo comitê do ALiB (2001). Os resultados apontam para uma variação produtiva em termos diatópicos e diastráticos. O item riacho/córrego apresenta 21 variantes, sendo que as mais recorrentes são riacho, córrego e igarapé. A variante riacho é predominante no nordeste, sudeste (exceto Belo Horizonte) e sul, enquanto córrego predomina no centro-oeste e igarapé no norte do Brasil. A influência social é mais relevante para as variantes lexicais riacho e córrego, que aparecem com mais frequência nas respostas dos informantes da segunda faixa etária, do sexo masculino e do ensino superior.
\end{abstract}

Palavras-chave: Dialetologia Pluridimensional. Variação lexical.

a Professor associado da UFPA e bolsista de produtividade em pesquisa do CNPq, arazky@gmail.com.

${ }^{\mathrm{b}}$ Mestrando em Letras, ênfase em Linguística, pela UFPA, duarte.romrio@gmail.com. 


\section{Introdução}

Um dos grandes desafios para uma pesquisa geolinguística, hoje, é descrever o léxico em aspectos geossociais que contemplem uma realidade em movimento. O Brasil, por ser um país de território vasto, com uma história interna demarcada por muitos processos migratórios, que culminaram na diversidade cultural e linguística, constitui um campo de experimentação importante para a documentação de sua diversidade lexical.

As particularidades lexicais do português brasileiro têm chamado atenção de muitos pesquisadores que se interessam pelo tema. Isquerdo (2006) afirma, de forma crítica, que muitos trabalhos, que compilam dados lexicais e os registram sob a forma de vocabulários, em sua maioria, de cunho regional, são produzidos, tanto por especialistas quanto por leigos, e nem sempre são pautados por critérios científicos.

Para Razky (2013), o léxico tem sido estudado por intermédio de várias perspectivas. Há, de um lado, pesquisas que se voltam para o estudo da história do léxico, descrevendo-o e analisando-o com base numa abordagem diacrônica. De outro, existem aquelas que, por meio da pesquisa de campo, registram o falar de determinadas comunidades linguísticas, num plano sincrônico, ou que fazem, ainda, um estudo léxicocomparativo entre o estado atual da fala e os documentos escritos em épocas anteriores. Os estudos acerca do léxico são heterogêneos, abrangendo diversas áreas, como a Lexicologia, a Lexicografia, a Terminologia, a Socioterminologia, entre outras.

De forma contundente, caberá aos estudos lexicais explicar o uso alternante de certas formas léxicas em determinadas condições linguísticas e extralinguísticas, bem como as diferentes unidades de origem geolinguística presentes em uma dada comunidade, na tentativa de identificar o léxico característico dos diferentes grupos sociais, como o léxico de faixa etária, de profissão, de escolaridade, entre outros fatores.

De acordo com Aragão (1999), as variações lexicais podem também ser, e geralmente são consideradas, ora como puramente geográficas (dialetais ou diatópicas), sociais (diastráticas), ou ainda dependentes do estilo (estilísticas ou diafásicas). 
Nesse contexto, acredita-se que a geolinguística tem dado grandes contribuições para o estudo do léxico, principalmente no que se denomina de macrocontribuição e microcontribuição.

A macrocontribuição prevê a documentação da diversidade lexical encontrada em dados geossociolinguísticos (aspecto espacial e social), tendo-a como patrimônio cultural de um povo. Por conseguinte, não basta apenas registrar e documentar, é preciso que esse conhecimento seja aplicado, por meio de políticas linguísticas, que forneçam contribuições à Lexicografia, à elaboração de dicionários, às cartilhas, aos manuais etc. A respeito da contribuição à Lexicografia, Isquerdo (2006) acredita que os atlas linguísticos têm fornecido significativas contribuições para a descrição das variações lexicais, pois podem fornecer aos lexicógrafos dados concretos para subsidiá-los quanto à inclusão de marcas dialetais de natureza diatópica, nos dicionários gerais da língua.

A microcontribuição objetiva descrever e analisar os fatos lexicais que podem se apresentar em diferentes dimensões, como a diatópica (topostática e topodinâmica), diastrática, diageracional, diagenérica, dialingual, diarreferencial e diafásica. Trata-se de uma análise intra e extralinguística.

\section{Geolinguística Pluridimensional}

Conforme Thun (1998), a Dialetologia Areal (tradicional) e a Sociolinguística, disciplinas historicamente separadas, confundem-se com uma geolinguística aprimorada que pode ser chamada de "Dialetologia Pluridimensional", compreendida como parte da ciência geral da variação linguística e das relações entre variantes e variedades, por um lado, e falantes, por outro. $\mathrm{O}$ autor ainda afirma que dentro dessa ciência geral, a dialetologia pluridimensional corresponde à parte da variação que se estende ao espaço tridimensional, ou seja, abrange a superfície bidimensional horizontal da dialetologia e o eixo vertical da sociolinguística, formando assim o espaço variacional tridimensional da dialetologia pluridimensional e relacional, como mostra a figura 01 . 
Figura 01 - Modelo da dialetologia pluridimensional e relacional

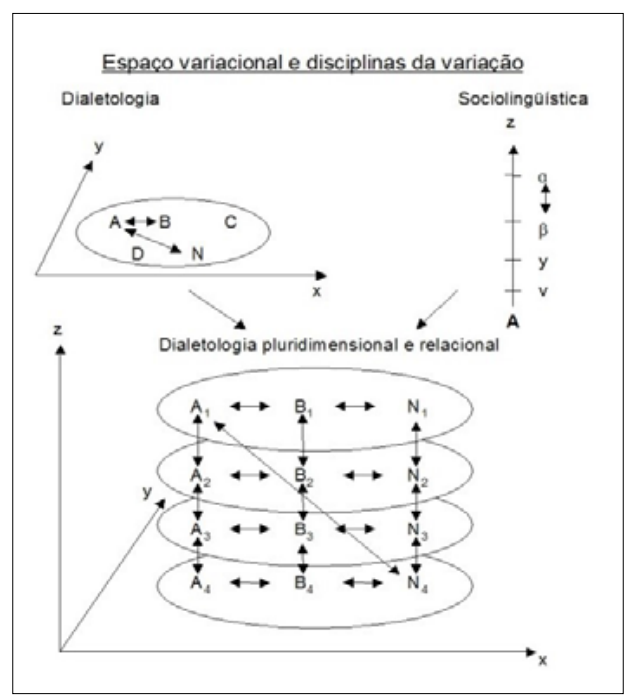

Fonte: RADTKE; THUN, 1996).

Para Thun (1998), conforme a figura 01, a Dialetologia pluridimensional deve analisar todos os planos (níveis de a - v; zonas parciais dos níveis; pontos das respostas: A $\mathrm{N}$; fragmentos dos pontos: grupos e indivíduos e todas as relações). Em suma, o que o autor propõe é uma descrição e análise da variação linguística, considerando os grupos de falantes, suas variáveis (idade, sexo, escolaridade, profissão e etc.) e as relações coexistente entre cada falante e espaço geográfico onde estes se encontram. Sendo assim, ele acredita que esse modelo de dialetologia passa a ser o ideal para descrição completa e ordenada do polimorfismo linguístico e de sua relação com os falantes.

A geolinguística pluridimensionale é também denominada de Dialetologia Pluridimensional e Relacional (THUN, 1998), de Geossociolinguística (RAZKY, 2003) e Sociodialetologia (GUY, 2012). Esse princípio de pluridimensionalidade, presente nas várias denominações para a geolinguística pluridimensional, fundamenta-se no modelo que engloba um conjunto de dimensões e parâmetros proposto por Thun (1998), como mostra a tabela 01 . 
Tabela 01 - Dimensões e parâmetros da dialetologia pluridimensional

\begin{tabular}{l|l}
\hline \multicolumn{1}{c|}{ Dimensões } & \multicolumn{1}{c}{ Parâmetros } \\
\hline Diatópica & Referente à variação geográfica \\
\hline Diastrática & Referente à variação por classe social \\
\hline Diageracional & Referente à variação por faixa etária \\
\hline Dialingual & Referente à variação por meio do contato linguístico \\
\hline Diafásica & Referente à variação da fala informal e formal \\
\hline Diarreferencial & Referente à questões metalinguísticas \\
\hline Diarreligiosa & Referente à variação influenciada pela religião \\
\hline Diamésica & Referente à variação do texto oral para o escrito \\
\hline
\end{tabular}

De acordo com Razky (2004), o advento da geolinguística pluridimensional tornou a análise de dados geolinguísticos mais complexa, pelo fato de permitir o cruzamento de dados na mesma localidade e entre localidades. Em decorrência disso, Razky (2013) afirma que o mapeamento de dados começa a revelar uma diversidade lexical no mesmo espaço físico, apesar de ainda se manterem as configurações de uma identidade local ou regional que passa a ser vista em termos estatísticos para estabelecer tendências e não características de identidades fixas.

Assim sendo, para Razky (2013), o conceito de isolexias passa, pouco a pouco, a ceder espaço a um conceito menos homogêneo, que pode ser chamado de agrupamentos, uma vez que, numa mesma localidade, podem ocorrer outras variações de menor uso, e que podem ser atestadas pela pesquisa de campo:

O conceito de agrupamento lexical vem acompanhando essa mudança em curso do léxico que, por sua vez, é fruto de uma mobilidade geográfica dos falantes e do acesso ao universo lexical do outro, através dos meios de comunicação. Além disso, o fluxo de interações verbais, fruto de redes de comunicações complexas, vem quebrando o paradigma de isolexias ou, pelo menos, o colocando dentro de um conceito do contínuo linguístico, bem conhecido dos estudos sociolinguísticos. (RAZKY, 2013, p. 263).

Como exemplo de agrupamentos lexicais, têm-se os primeiros resultados apresentados no Atlas Linguístico do Brasil (2014). Segundo Razky (2013), são dados que demonstram que o conceito de isoglossa precisa ser revisto à luz das mudanças linguísticas em curso no português brasileiro. Outra contribuição da geolinguística pluridimensional é diminuir 
a força centralizadora de algumas variantes lexicais que apareciam de forma homogênea em alguns atlas linguísticos regionais da primeira geração.

Os resultados de uma descrição lexical que contempla a realidade linguística de todas as regiões brasileiras, dentro dessa dinâmica pluridimensional, aparecem na publicação dos primeiros volumes do Atlas Linguístico do Brasil - ALiB, lançado em outubro de 2014, durante o Congresso Internacional de Dialetologia e Sociolinguística (III CIDS), realizado na Universidade Estadual de Londrina (UEL).

Alguns aspectos da tapeceira lexical brasileira, tradadas no volume 2, do ALIB (Cardoso \& al. 2014), já demonstram a importância para o país de ter, pela primeira vez, sua riqueza lexical cartografada em dimensões geográficas e sociais dentro de uma estratificação geossociolinguística representativa, em um Brasil do século 21.

O projeto ALiB contou com 1100 informantes e estabeleceu uma rede de pontos constituída de 250 localidades distribuídas por todo o território brasileiro. Foram aplicados três tipos de questionários, cada um deles, especificamente, direcionados para os aspectos fonético-fonológicos, semântico-lexicais e morfossintáticos. Além disso, acrescentam-se, a esses três tipos de questionários, questões de pragmática, temas para discursos semidirigidos, perguntas metalinguísticas e texto para leitura (CARDOSO, 2010).

\section{Metodologia}

Adota-se, como procedimento metodológico, o método da geolinguística pluridimensional. Os dados analisados compõem o corpus do projeto Atlas Linguístico do Brasil ALiB, cujo objetivo é mapear e descrever a língua falada em uma rede de pontos de 250 localidades distribuídas por todo o território nacional.

Para esta pesquisa, contemplamos apenas 25 capitais brasileiras, são elas: Amapá, Roraima, Amazonas, Pará, Acre, Rondônia, Maranhão, Piauí, Ceará, Rio Grande do Norte, Paraíba, Pernambuco, Alagoas, Sergipe, Bahia, Mato Grosso, Mato Grosso do Sul, Goiás, Minas Gerais, São Paulo, Espírito Santo, Rio de Janeiro, Paraná, Santa Catarina e Rio Grande do Sul. Abaixo segue o mapa explicativo (figura 02) com todos os pontos selecionados. 
Figura 02 - Rede de pontos do ALiB

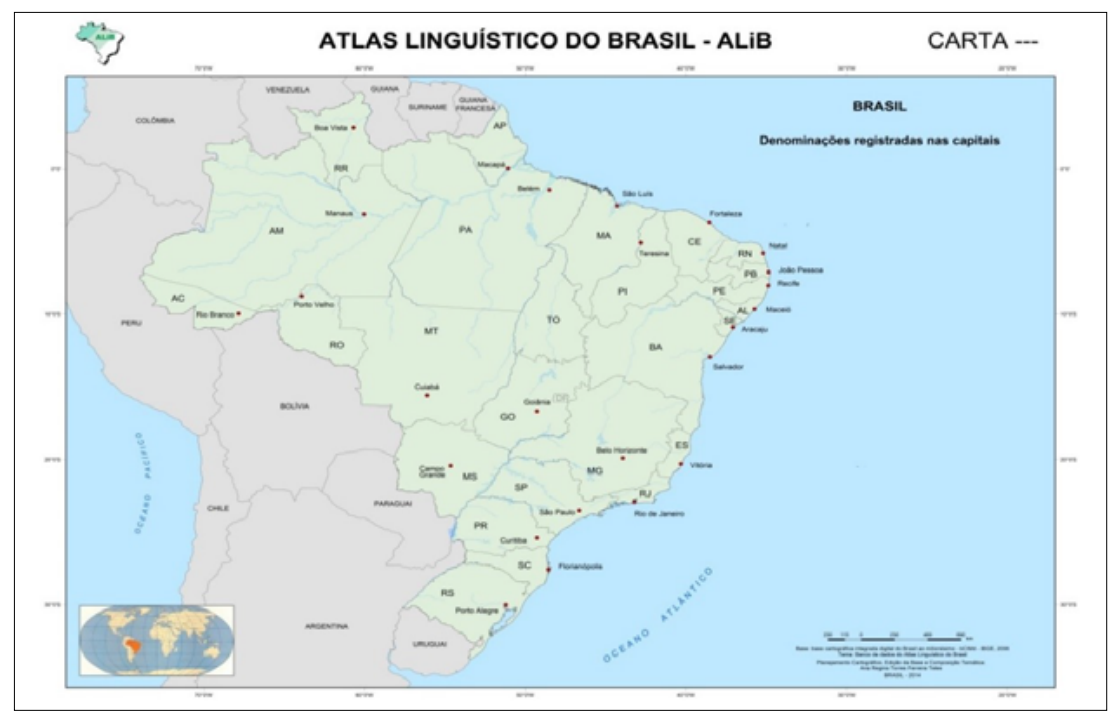

O perfil dos informantes segue os parâmetros elaborados pelo comitê do ALiB (COMITÊ, 2001). Este estudo contempla 8 informantes em cada uma das 25 capitais do projeto no $\mathrm{ALiB}$, considerando três variáveis, a saber: sexo, faixa etária e escolaridade.

Neste sentido, como mostra a tabela 01 , tem-se o seguinte perfil para os informantes: 4 homens e 4 mulheres, sendo 1 homem e 1 mulher com faixa etária entre 18 a 30 anos, com ensino fundamental completo ou incompleto; 1 homem e 1 mulher com o mesmo grau de escolaridade, mas com faixa etária entre 50 a 65 anos. A estes 4 primeiros informantes acrescentam-se mais 4 com o mesmo perfil de idade e sexo, no entanto, com nível de escolaridade superior (universitário).

Tabela 02 - Perfil dos informantes

\begin{tabular}{c|c|c|c}
\hline Informantes & Faixa etária & Sexo & Escolaridade \\
\hline 01 & $18-30$ & Masculino & Fundamental \\
\hline 01 & $18-30$ & Masculino & Universitário \\
\hline 01 & $50-65$ & Masculino & Fundamental \\
\hline 01 & $50-65$ & Masculino & Universitário \\
\hline 01 & $18-30$ & Feminino & Fundamental \\
\hline 01 & $18-30$ & Feminino & Universitário \\
\hline 01 & $50-65$ & Feminino & Fundamental \\
\hline 01 & $50-65$ & Feminino & Universitário \\
\hline
\end{tabular}


O item lexical córrego/riacho, objeto de análise desta pesquisa, pertence ao campo semântico acidentes atmosféricos do Questionário Semântico-Lexical do ALiB. Busca-se encontrar as denominações para "um rio pequeno de uns dois metros de largura.". Os dados obtidos foram tratados da seguinte forma: i) organização de todas as respostas esperadas e não esperadas em uma Planilha Excel, identificando a localidade e o perfil do informante; ii) quantificação dos dados em porcentagens; iii) elaboração das cartas linguísticas: diatópica, diageracional, diastrática e diagenérica; e, por fim, iv) análise dos resultados.

\section{Descrição e análise dos resultados}

Duas análises do item lexical riacho/córrego são propostas aqui. Uma análise espacial, que aborda a descrição das variantes lexicais do ponto de vista diatópico geral, regional e local; e uma análise social, que verifica a influência da faixa etária, sexo e escolaridade.

\subsection{Análise espacial}

Para análise espacial serão expostos dois tipos de análise. A primeira análise investiga todas as respostas dadas à variável lexical riacho/córrego por cada informante em todas as localidades, com objetivo de ter uma face da visão pluridimensional sobre todos os usos linguísticos do ponto de vista diatópico presentes numa localidade. A segunda analisa, especificamente, apenas a primeira resposta dada por cada informante em todas as capitais brasileiras. Embora esta última análise reduza o escopo variacionista dentro de cada localidade, pelo fato de considerar apenas uma resposta, ela permitirá destacar os usos mais característicos de cada localidade. Deste modo, as duas análises, como veremos, são complementares, pois permitem melhor situar os agrupamentos lexicais.

\subsubsection{Análise de todas as respostas de cada informante}

O primeiro resultado inédito do ponto de vista geográfico é o número de variantes registrados para o item lexical analisado. São 21 variantes lexicais entre as capitais brasileiras: riacho, córrego, igarapé, lago, lagoa, riozinho, rego, açude, poço, ribeirão, rio pequeno, furo, canal, paraná, curixó, coxipó, ribeirinho, perna do rio, braço do rio, corrente e regato. Essa produtividade lexical tem 
sido registrada em vários outros estudos sobre os dados das capitais brasileiras no ALiB (Cardoso \& al., 2014). Para otimizar o mapeamento dos dados foram analisadas somente as variantes mais frequentes, como mostra a carta diatópica, na figura 03.

Figura 03 - Carta diatópica do item lexical riacho/córrego

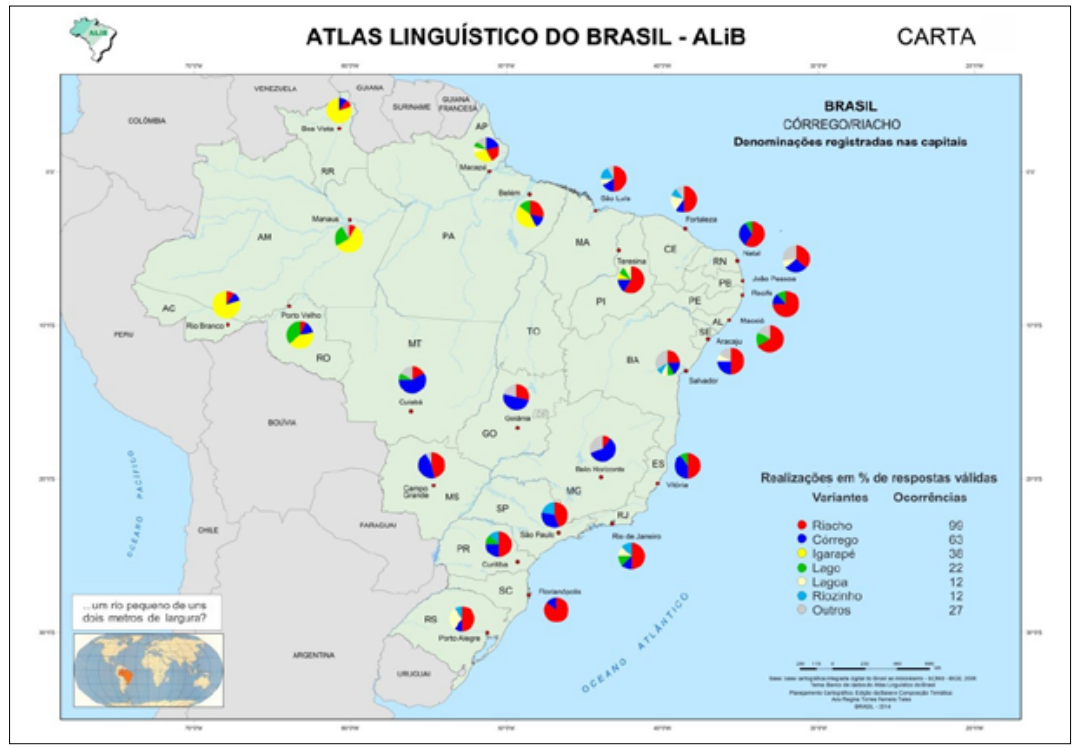

Uma primeira leitura, da figura 03, aponta para a realização de 6 variantes lexicais mais frequentes nas capitais brasileiras: riacho, córrego, igarapé, lago, lagoa e riozinho.

Em termos percentuais gerais, calculados em função de todas as outras variantes catalogadas como outros (gráfico 01), a variante lexical riacho aparece com $36 \%$ de ocorrência. Em seguida aparece córrego com $23 \%$, igarapé com $14 \%$, lago com $7 \%$, lagoa com $5 \%$ e riozinho com $5 \%$. As demais, 14 variantes pouco produtivas, somam uma frequência de $10 \%$.

Gráfico 01 - Percentual das variantes

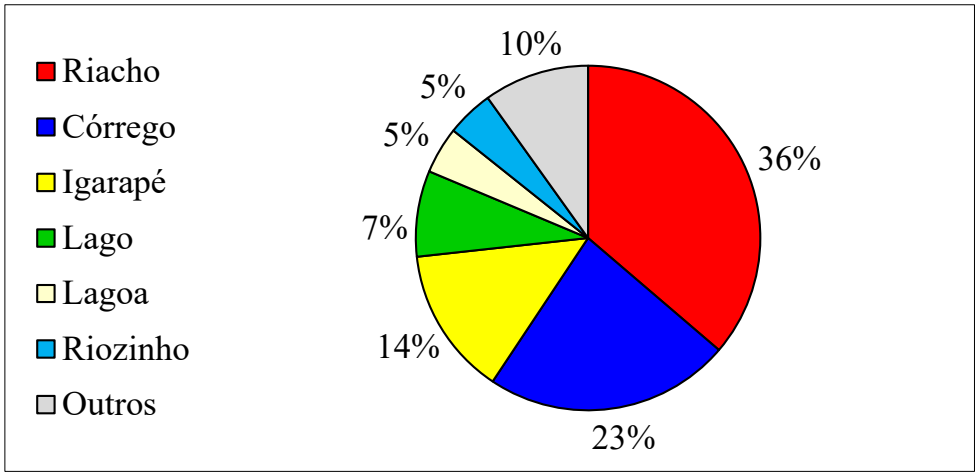


As lexias riacho e córrego estão presentes em todo o território nacional, salvo em Manaus, São Luís e Maceió, onde não houve o registro de córrego. A variante lexical igarapé concentra-se primordialmente nas capitais da região norte, no entanto, conforme mostra a figura 03 , tal variante também se apresentou na capital Teresina, no nordeste, onde obteve apenas um registro. As demais variantes aparecem distribuídas em todas as regiões do Brasil, com frequências menores, como é possível constatar na tabela 03 , a seguir.

Tabela 03 - Percentual de frequência das variantes

\begin{tabular}{|c|c|c|c|c|c|c|c|c|}
\hline \multirow[t]{2}{*}{ REGIÃO } & $\begin{array}{c}\text { ITEM } \\
\text { LEXICAL }\end{array}$ & \multirow[t]{2}{*}{ RIACHO } & \multirow[t]{2}{*}{ CÓRREGO } & \multirow[t]{2}{*}{ IGARAPÉ } & \multirow[t]{2}{*}{ LAGO } & \multirow[t]{2}{*}{ LAGOA } & \multirow[t]{2}{*}{ RIOZINHO } & \multirow[t]{2}{*}{ OUTROS } \\
\hline & CAPITAL & & & & & & & \\
\hline \multirow[t]{6}{*}{ NORTE } & Manaus & $8 \%$ & - & $59 \%$ & $25 \%$ & - & - & - \\
\hline & Rio Branco & $10 \%$ & $10 \%$ & $80 \%$ & - & - & - & - \\
\hline & Porto Velho & $15 \%$ & $8 \%$ & $46 \%$ & $31 \%$ & - & - & - \\
\hline & Boa Vista & $10 \%$ & $10 \%$ & $80 \%$ & - & - & - & - \\
\hline & Macapá & $20 \%$ & $20 \%$ & $33 \%$ & $7 \%$ & $7 \%$ & - & $14 \%$ \\
\hline & Belém & $29 \%$ & $14 \%$ & $43 \%$ & $14 \%$ & & - & - \\
\hline \multirow[t]{9}{*}{ NORDESTE } & Fortaleza & $50 \%$ & $10 \%$ & - & - & $20 \%$ & $10 \%$ & $10 \%$ \\
\hline & Natal & $59 \%$ & $33 \%$ & - & $8 \%$ & - & - & - \\
\hline & Teresina & $59 \%$ & $17 \%$ & $8 \%$ & $8 \%$ & $8 \%$ & - & - \\
\hline & São Luís & $55 \%$ & - & - & $18 \%$ & $9 \%$ & - & $18 \%$ \\
\hline & Recife & $67 \%$ & $11 \%$ & - & $11 \%$ & - & - & $11 \%$ \\
\hline & João Pessoa & $40 \%$ & $20 \%$ & - & - & $10 \%$ & $10 \%$ & $20 \%$ \\
\hline & Maceió & $57 \%$ & & - & $15 \%$ & - & $14 \%$ & $14 \%$ \\
\hline & Aracaju & $50 \%$ & $25 \%$ & - & - & $9 \%$ & - & $16 \%$ \\
\hline & Salvador & $28 \%$ & $18 \%$ & - & $9 \%$ & $9 \%$ & $9 \%$ & $27 \%$ \\
\hline \multirow[t]{3}{*}{ CENTRO-OESTE } & Cuiabá & $15 \%$ & $61 \%$ & - & $8 \%$ & - & - & $16 \%$ \\
\hline & Campo Grande & $43 \%$ & $50 \%$ & - & - & - & - & $7 \%$ \\
\hline & Goiânia & $29 \%$ & $50 \%$ & - & - & - & - & $21 \%$ \\
\hline \multirow[t]{4}{*}{ SUDESTE } & Belo Horizonte & $18 \%$ & $55 \%$ & - & - & - & - & $27 \%$ \\
\hline & $\begin{array}{l}\text { Vitória } \\
\end{array}$ & $46 \%$ & $36 \%$ & - & $9 \%$ & - & - & $9 \%$ \\
\hline & Rio de Janeiro & $45 \%$ & $11 \%$ & - & $11 \%$ & $22 \%$ & $11 \%$ & - \\
\hline & São Paulo & $45 \%$ & $33 \%$ & - & - & - & $22 \%$ & - \\
\hline \multirow[t]{3}{*}{ SUL } & Curitiba & $50 \%$ & $25 \%$ & - & $12 \%$ & - & $13 \%$ & - \\
\hline & Florianópolis & $75 \%$ & $12 \%$ & - & - & - & $13 \%$ & - \\
\hline & Porto Alegre & $50 \%$ & $10 \%$ & - & $20 \%$ & $10 \%$ & $10 \%$ & - \\
\hline
\end{tabular}

A partir da tabela 03 e da carta diatópica (figura 03) é possível inferir que os itens riacho, córrego e igarapé apresentam uma configuração espacial de agrupamentos lexicais (RAZKY, 2013). O conceito de agrupamento lexical aplicado à dialetologia permitiu o desenvolvimento das abordagens pluridimensionais. Os resultados do ALiB mostram que a metodologia pluridimensional contribui para diminuir a força centralizadora de algumas variantes lexicais que apareciam numa forma homogênea em alguns atlas linguísticos regionais 
${ }^{3}$ Podemos afirmar o valor do espaço geográfico até dentro de subáreas definidas politicamente como regiões. Os estudos sociolinguísticos no Brasil que se dedicam a áreas muito limitadas, como a descrição de uma cidade, muitas vezes, acabam frequentemente por generalizar ou induzir a generalizações de seus resultados para áreas vizinhas, criando, assim, dialetos imaginários, enquanto a variação linguística está sujeita (é assunto par) a muitas variáveis e a variável geográfica tem um peso muito grande. Outros estudos, por terem como objetivo áreas geográficas extensas e uma amostragem reduzida, podem também ignorar a riqueza que uma boa estratificação social pode produzir. É nesse sentido que defendemos a abordagem geossociolinguística. da primeira geração. Os resultados, por exemplo, da variação riacho/córrego sugerem uma mudança notável no esquema proposto por Nascentes para a divisão dialetal brasileira, uma vez que mudanças dentro do contínuo rural-urbano apontam para uma reorganização do espaço lexical brasileiro em que não é possível traçar isolexias perfeitas, mas apenas agrupamentos lexicais. Esses agrupamentos são suscetíveis de mudanças dependendo do grau e natureza de estratificação geossocial proposta.

O fato não se limita apenas à dimensão lexical, pois outras pesquisas de natureza fonética já registraram essa mudança dentro de fronteiras interestaduais. Razky (2010) observa essa mudança de perspectiva motivada pela introdução de variáveis sociodialetais (espaço geográfico e espaço social), ao afirmar:

ilnous est possible d'affirmer la valeur del'espace géographique même dans des sous-espaces définis politiquement comme les régions. Les études sociolinguistiques au Brésil qui se sont consacrées à des espaces très limités, comme la description d'une ville, finissent souvent par généraliser ou induire à des généralisations de leur résultas aux espaces voisins créant ainsi des dialectes imaginaires, alors que la variation linguistique est sujette à beaucoup plus de variables et que la variable géographique a un poids très important. D'autres études, pour avoir comme objetctif des espaces géographiques étendus et un échantillonnage réduit, peuvent aussi laisser de côté la richesse qu'une bonne stratification sociale peut produire. C'est dans ce sens que nous défendons la démarche géossociolinguistique. (RAZKY, 2010, p. 329) 3

Um dos fortes agrupamentos da variável lexical analisada aqui é a variante igarapé, que apresenta uma frequência forte no norte do Brasil, conforme a figura 03. Entretanto, pelo fato de termos uma dinâmica geossocial de 06 localidades, 48 informantes estratificados por sexo, idade e escolaridade, podemos observar que os resultados não são homogêneos em nenhuma localidade, o que sugere a presença de outras variantes com uma frequência menor, mas que mantêm o contínuo territorial representado pelas variantes riacho e córrego. Outra tendência, que aparece nesse resultado, é a linha descendente de frequência no uso da variante igarapé, do oeste para o leste da região norte, conforme o gráfico 02; saindo da região norte, a variante igarapé registra $8 \%$ em Teresina, capital 
do Piauí, o que corrobora ao contínuo de enfraquecimento no uso da lexia igarapé, na direção supracitada.

Gráfico 02 - Agrupamento lexical da variante ígarapé

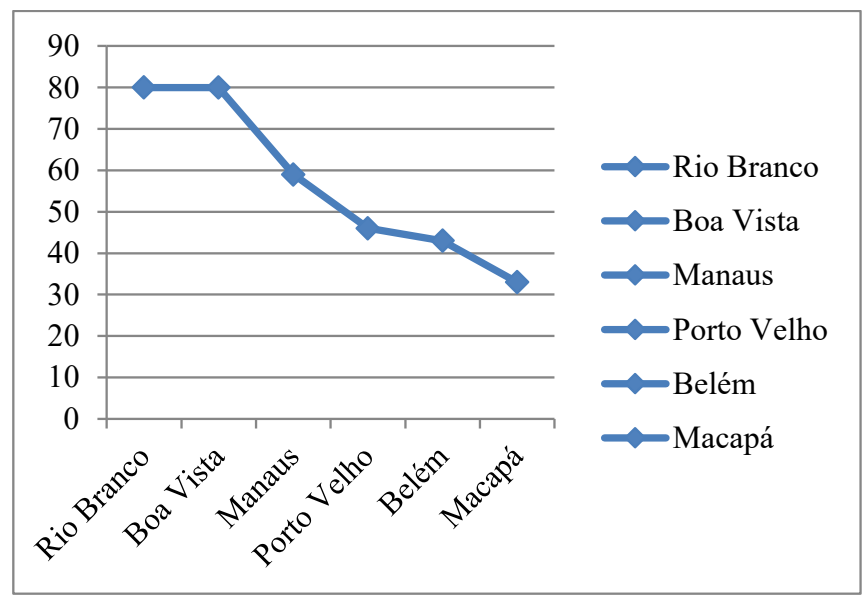

O agrupamento lexical destacado aqui, não caracteriza uma isolexia devido à descrição mais realista da geolinguística pluridimensional e ao fato de que os falantes vivem hoje numa rede de comunicação que conhece uma estabilidade frágil devido aos processos de mobilidade populacional e aos processos remoduladores dos mais diversos tipos de mídia, impressas e eletrônicas, que fazem do espaço geolinguístico um espaço ecolinguístico mais complexo.

Um segundo agrupamento lexical mais amplo na sua extensão geográfica, porém menos marcado em frequência de uso, conforme a tabela 03, é o da variante lexical riacho. Em ordem de frequência de agrupamentos (gráfico 03), a linha descendente marca o nordeste em primeiro lugar, seguido do sul e depois do sudeste brasileiro. Nota-se, portanto, que em Belo Horizonte, região sudeste, a variante riacho apresenta apenas $18 \%$ de uso em relação à variante córrego com 55\%, o que indica que as mudanças geossociais no Brasil geraram movimentos de variação lexical dentro de espaços menores em que os atlas linguísticos regionais monodimensionais e bidimensionais não cartografaram. Isso aconteceu em decorrência da metodologia da pesquisa de campo, pelo fato desses atlas não terem envolvido amostras representativas de nível diatópico e diastrático em todos os pontos de inquéritos. 
Gráfico 03 - Agrupamento lexical da variante riacho

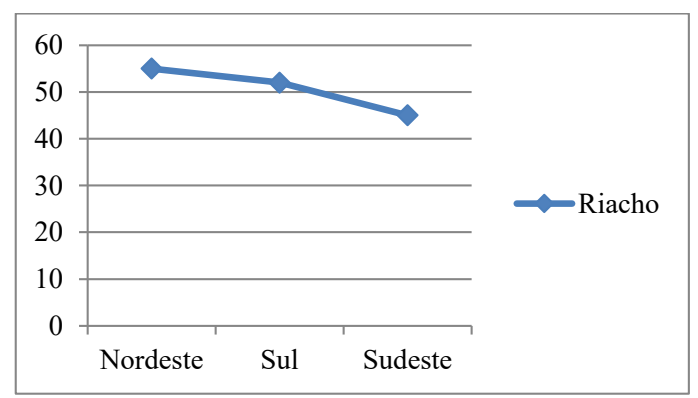

Um terceiro agrupamento lexical que se destaca no mapa diatópico (figura 03), concerne à variante córrego que indica uma frequência de uso maior na região centro-oeste (Cuiabá 61\%, Campo Grande 50\%, Goiânia 50\%) e em Belo Horizonte, sudeste, com uma frequência média de $53 \%$.

\subsubsection{Análise da primeira resposta de cada informante}

Ao analisar a primeira resposta de cada informante, cartografou-se a variante com maior frequência em cada capital. Um mapeamento considerando apenas a primeira resposta de cada informante reduz o contínuo variável presente em cada informante, em cada localidade e em cada região. Assim, a figura 04 desenha uma nova configuração, com características presentes na figura 03, dando um destaque para um mapeamento característico de isolexias provavelmente presentes na história geossocial em cada localidade, mas que sofreram influências, como já mencionadas anteriormente.

O resultado da carta apresentada aqui, figura 03, com a primeira variante mais frequente em cada capital brasileira, demonstra a validade do conceito de agrupamento lexical dentro de uma variação pluridimensional que contém 3 agrupamentos lexicais, já que observamos a predominância de 3 variantes acompanhadas de outras com menor frequência numa mesma localidade. Podemos então traçar 3 divisões geográficas de agrupamentos lexicais mais produtivas em cada região (figura 04). Essas divisões constituem uma abstração exploratória da resposta mais frequente em cada ponto de inquérito, em que apresenta o agrupamento lexical geral da análise diatópica pluridimensional. 
Figura 04 - Variantes mais frequentes por capital, considerando a primeira resposta.

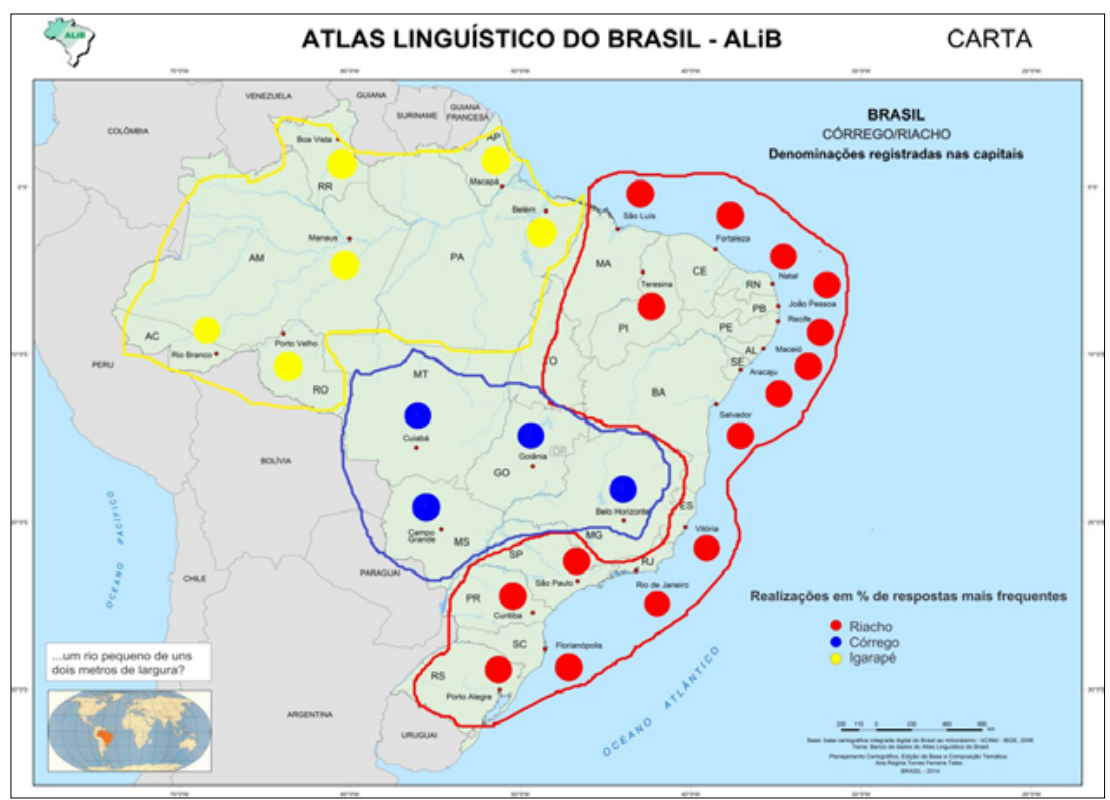

Como podemos observar na figura acima, os 3 agrupamentos lexicais delimitados aqui estão restritos às variantes riacho, córrego e igarapé. Ressaltamos que esta configuração só foi possível considerando apenas a primeira resposta do informante. A seguir, apresentaremos a análise social destas variantes lexicais mais frequentes considerando as variáveis: faixa etária, sexo e escolaridade.

\subsection{Análise social}

Para análise do aspecto social do item em questão, levaram-se em consideração três variáveis: faixa etária, sexo e escolaridade. Foram elaboradas três cartas linguísticas para verificar cada variável, ou seja, como as variantes lexicais mais frequentes (riacho, córrego e igarapé) se comportam em relação à idade, sexo e escolaridade do informante. Na tentativa de constatar se os usos linguísticos de certas variantes estão interligados com as variáveis sociais.

A tabela 04, a seguir, apresenta o percentual de frequência de todas as variáveis e, ao lado, o número de ocorrências, seguida da análise e das cartas linguísticas. 
Tabela 03 - Distribuição por variáveis sociais

\begin{tabular}{|c|c|c|c|c|c|c|c|c|c|c|c|c|}
\hline \multirow{4}{*}{ Variantes } & \multicolumn{4}{|c|}{ Faixa etária } & \multicolumn{4}{|c|}{ Sexo } & \multicolumn{4}{|c|}{ Escolaridade } \\
\hline & \multicolumn{2}{|c|}{ A } & \multicolumn{2}{|c|}{ B } & \multirow{2}{*}{\multicolumn{2}{|c|}{$\mathrm{H}$}} & \multirow{2}{*}{\multicolumn{2}{|c|}{ M }} & \multicolumn{2}{|c|}{1} & \multicolumn{2}{|c|}{2} \\
\hline & \multicolumn{2}{|c|}{$18-30$} & \multicolumn{2}{|c|}{$50-65$} & & & & & \multicolumn{2}{|c|}{ Fundamental } & \multicolumn{2}{|c|}{ Superior } \\
\hline & $\%$ & Oco. & $\%$ & Oco. & $\%$ & Oco. & $\%$ & Oco. & $\%$ & Oco. & $\%$ & Oco. \\
\hline Riacho & $39 \%$ & 37 & $61 \%$ & 57 & $54 \%$ & 58 & $46 \%$ & 49 & $34 \%$ & 32 & $66 \%$ & 62 \\
\hline Córrego & $43 \%$ & 26 & $57 \%$ & 35 & $65 \%$ & 30 & $35 \%$ & 16 & $44 \%$ & 25 & $56 \%$ & 32 \\
\hline Igarapé & $50 \%$ & 19 & $50 \%$ & 19 & $55 \%$ & 21 & $45 \%$ & 17 & $47 \%$ & 18 & $53 \%$ & 20 \\
\hline
\end{tabular}

Uma característica dos atlas linguísticos de terceira geração, que integram o componente social, é a possiblidade de projetar a influência de variáveis extralinguísticas nas próprias cartas linguísticas para facilitar a leitura social dos dados cartografados.

Uma primeira estratificação social, a notar, em relação à faixa etária, é a frequência significativa de córrego e riacho, com uso respectivo de $61 \%$ e $57 \%$ pelos informantes da segunda faixa etária. A variante lexical igarapé, por sua vez, não tem um peso na distribuição por idade, pois apresenta uma frequência de uso igual a $50 \%$, observada para ambas as faixas etárias.

A carta linguística pluridimensional na figura 05 apresenta esses resultados distribuídos por localidade e faixa etária.

Figura 05 - Variação diageracional do item riacho/córrego por localidade e faixa etária

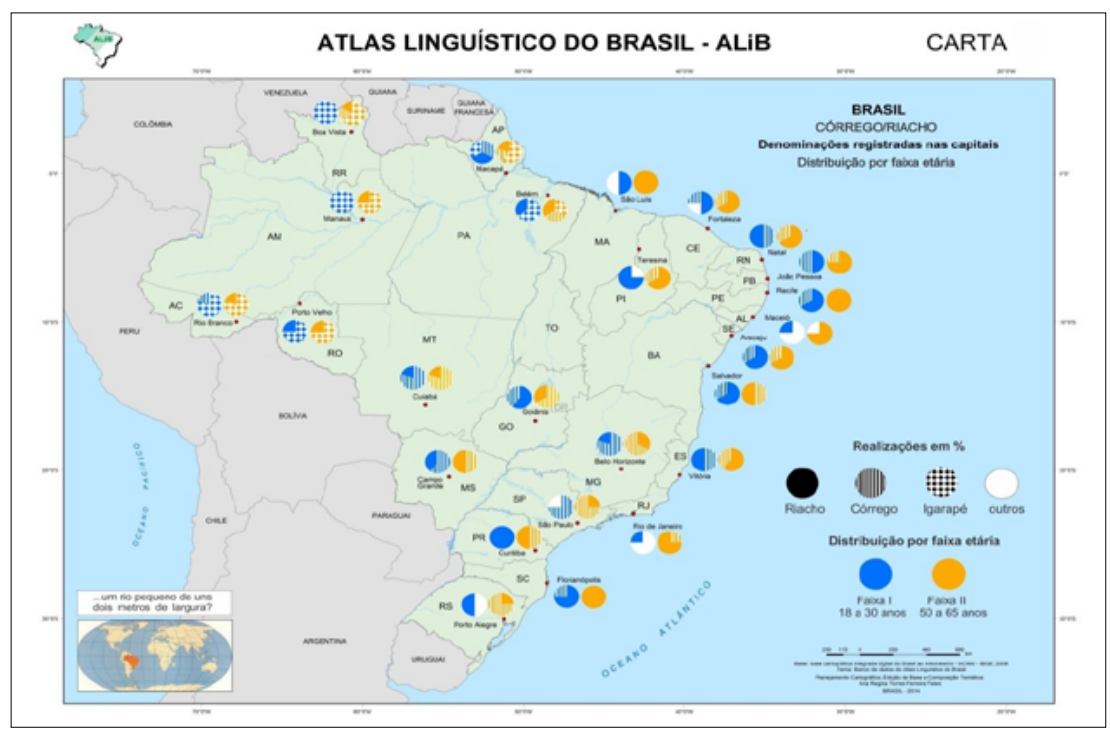


A variável sexo, como aparece na figura 06 e na tabela 03, mostra que os homens tendem a utilizar mais os itens lexicais riacho (54\%), córrego (65\%) e igarapé (55\%); para as mulheres os valores respectivos são $46 \%, 35 \%$ e $45 \%$. A variante córrego apresentou uma frequência de uso muito significativa pelos homens em relação às outras variantes. Não cabe, portanto, aqui, pela natureza do trabalho, explicar porque os dados tendem a ter essa configuração, pois, até então, nenhuma dessas variantes serviu de teste de prestígio ou percepção simbólica diagenérica. Mas a influência da variável sexo é atestada para a variável lexical nas capitais brasileiras.

Figura 06 - Variação diagenérica do item riacho/córrego por localidade e sexo

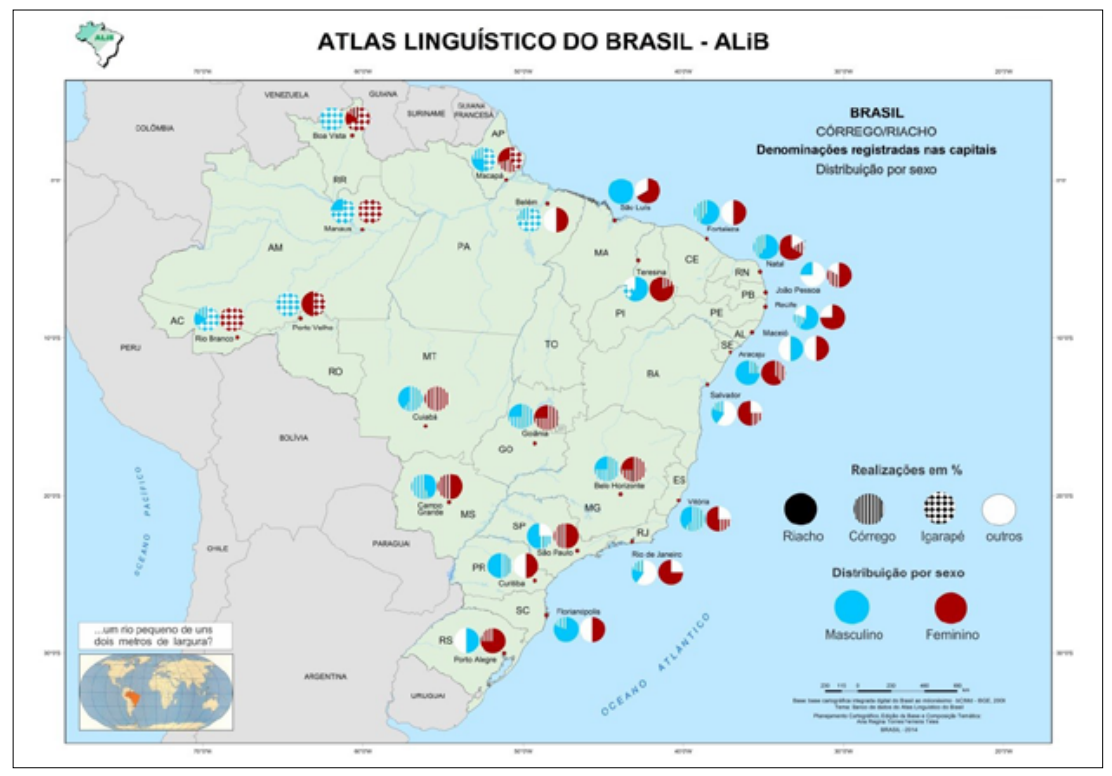

Já a carta lexical, da figura 07, mostra que os informantes de ensino superior, das capitais brasileiras, tendem a responder, de forma significativa, à pergunta: "aquele rio pequeno com dois metros de largura.", utilizando a variante riacho, córrego e igarapé. Riacho obteve 34\% entre os informantes de nível fundamental e $66 \%$ entre os de nível superior; córrego obteve $44 \%$ entre os informantes de nível fundamental e $56 \%$ entre os de nível superior e igarapé obteve $47 \%$ entre os informantes de nível fundamental e $53 \%$ entre os de nível superior. 
Figura 07 - Variação diagenérica do item riacho/córrego por localidade e escolaridade

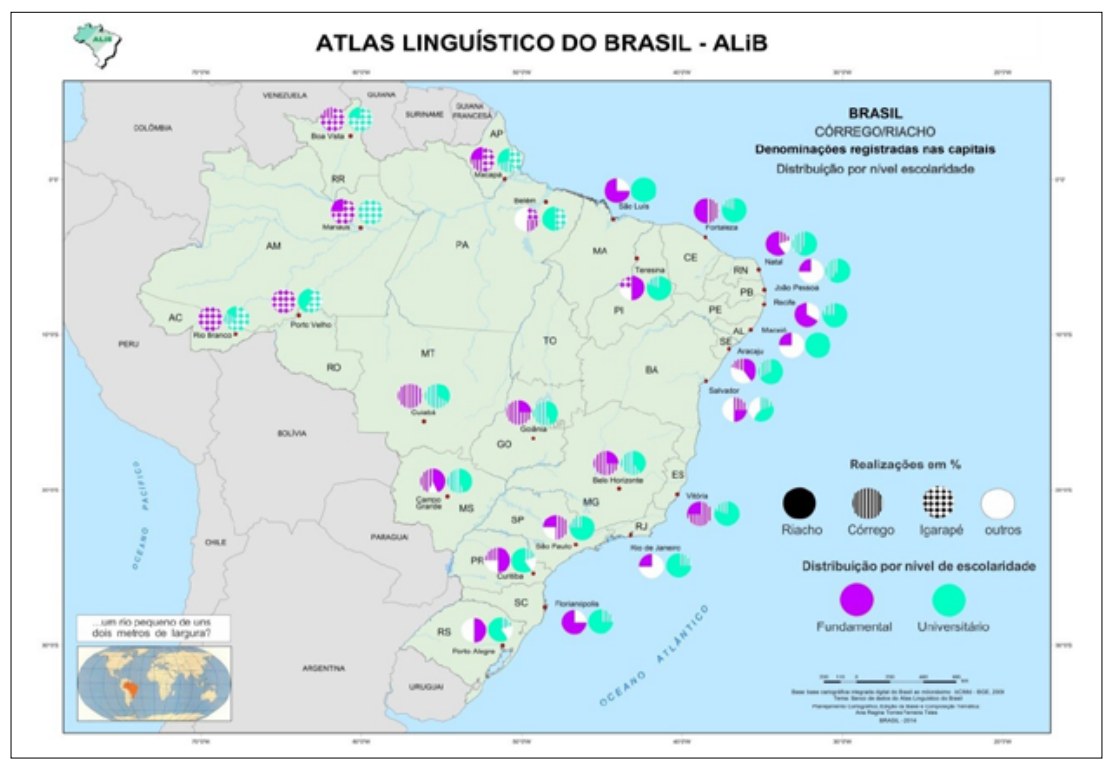

A análise das três variáveis (idade, sexo e escolaridade) correspondentes às três variantes mais produtivas (riacho, córrego e igarapé), regional e nacionalmente, sugere que a variante igarapé pode ser considerada como variante do tipo estável, ou seja, passa ser estável pelo fato de sua abrangência geográfica estar fortemente fixada no norte brasileiro, sem variantes concorrentes marcadas socialmente. A variante córrego, a segunda variante mais produtiva nas capitais brasileiras, é uma variante relativamente instável com uma pressão significativa das variáveis sociais: idade, sexo e escolaridade (50-65 anos, homens e universitários). Riacho, por sua vez, a primeira variante mais produtiva no Brasil, destaca-se como variante instável, pois recebe uma forte influência social igual àquela de córrego (50-65 anos, homens e universitários). Assim, as variantes riacho e córrego podem ser classificadas como variantes concorrentes, na maior parte do território brasileiro. Não se trata, portanto, de falar de uma mudança lexical em curso, pois as duas variantes continuam produtivas, têm uma estratificação diatópica e os falantes que mais as utilizam têm perfil universitário compatível com uma norma de prestígio. 


\section{Considerações finais}

A exploração da variável lexical riacho/córrego, nesta pesquisa inédita, no banco de dados do projeto $\mathrm{ALiB}$, oferece uma imagem mais autêntica de uma parcela da riqueza lexical presente nas capitais brasileiras. A metodologia de uma estratificação pluridimensional ou geossociolinguística permitiu um levantamento de 21 variantes lexicais cuja análise depende do conjunto de fatores geossociais representativos da realidade brasileira. Os resultados sugerem um recorte geral em frequências de uso mais produtivas no espaço investigado. Desse recorte, destacam-se as variantes riacho (36\%), córrego (23\%) e igarapé (14\%). A análise espacial evidencia o uso da variante riacho no nordeste, sul e sudeste (Belo Horizonte). $\mathrm{O}$ centro-oeste acentua o uso de córrego, enquanto o norte aponta para um uso majoritário da variante igarapé. A análise social salienta as variantes riacho e córrego na fala dos informantes de segunda faixa etária, de sexo masculino e de ensino superior. No entanto, a variante igarapé não parece ter uma restrição que possa justificar uma estratificação vertical e, por isso, foi considerada como variante estável na perspectiva diastrática.

Em suma, riacho e córrego aparecem como variantes lexicais em concorrência, por compartilharem estatisticamente espaços comuns. Os mesmos itens também aparecem em coocorrência com igarapé, pois este último predomina de forma muito significativa no norte brasileiro. Em outra análise, fezse a abstração da variabilidade além da primeira resposta dos informantes e considerou-se um cálculo de frequência maior por região (figura 04), confirmando assim, uma configuração cartográfica dos 03 agrupamentos lexicais no Brasil. Esses agrupamentos podem ser classificados como homogêneos, se considerados a partir do processo de abstração que pode levar a traçar uma isolexia, ou seja, se considerarmos apenas a primeira resposta do informante; e classificados como heterogêneos, se integrados numa descrição pluridimensional, considerando não só a primeira resposta, mas todas as respostas ditas pelo informante. Assim, insistimos na reformulação do conceito de isolexia a favor do conceito de agrupamento lexical. 


\section{REFERÊNCIAS}

ARAGÃO, Maria do Socorro. Variação Fonético-lexical em Atlas Linguísticos do Nordeste. Revista do GELNE, Ano 1. n. 1, 1999.

BASÍLIO, Maria. Teoria Lexical. 8. ed. São Paulo: Ática, 2007.

CARDOSO, Suzana (et al.). Atlas Linguístico do Brasil: cartas linguísticas 1. Londrina: EDUEL, 2014.

CARDOSO, Suzana. Geolinguística: tradição e modernidade. São Paulo: Parábola, 2010.

GUY, Gregory. Rumos da sociodialetologia da América Latina. In: Congresso Internacional de Dialetologia e Sociolinguística (2. : 2012 : Belém, PA). Diversidade linguística e políticas de ensino: anais. Coord. Abdelhak Razky, Marilúcia Barros de Oliveira, Alcides Fernandes de Lima. São Luís: EDUFMA, 2012. p. 44-60.

ISQUERDO, Aparecida Negri. Lexicografia e Geolinguística: interfaces. In: MARTINS, Evandro (org.). Léxico e morfofonologia: perspectivas e análises. Uberlâdia: EDUFU, 2006. p. 113-133.

COMITÊ NACIONAL DO PROJETO ALiB: Atlas Linguístico do Brasil. Questionários. Londrina: UEL, 2001.

RAZKY, Abdelhak. A Dimensão Sociodialetal do Léxico no Projeto Atlas Linguístico do Brasil. SIGNUM: Estud. Ling., Londrina, n. 16/2, p. 247-270, dez. 2013.

. La variation phonétique entre sociolinguistique et géographie linguistique. Revista Lenguaje, 2010. p. 314-330.

RAZKY, Abdelhak. (org.). Estudos geossociolinguísticos no Estado do Pará. Belém: s/ed., 2003.

(org.) Atlas linguístico sonoro do Pará. Belém: UFPA; CAPES; UTM, 2004. [1 CD-Rom].

RADTKE, Edgar; THUN, Harald. Nuevos caminos de la geolinguística románica. Un

balance. In: RADTKE, Edgar; THUN, Harald. Neue Wege der Romanischen Geolinguistik. Kiel: Westensee-Verlag, 1996. p. 25-49. 
THUN, Harald. La géographie linguistique romane à la fin du XX esiècle. In: Congres International de Linguistique et de Philologie Romanes, 22., 1998, Bruxelles. ACTES. Tübingen: Niemeyer, 2000. p.367-388.

La geolingüística como lingüística variacional general (com ejemplos del Atlas linguístico Diatópico y Diastrático del Uruguay). In: International Congress of Romance Linguistics and Philology. Tübingen: Niemeyer, 1998. v. 5, p. 701-729.

\section{Abstract \\ Geossocial variation of the lexical item riacho/ córrego in brazilian cities}

The aim of this study is to analyze and map the lexical variation of the lexical item riacho/corrego from the point of view of the multidimensional dial ${ }^{*} e c t o l o g y$ (THUN, 2000), thus integrating them to the methodological framework of geossociolinguistic (RAZKY, 2004; 2013). The data analyzed here, in the geossocial perspective, make up a knowledge base on the Brazilian Portuguese of the national project Linguistic Atlas of Brazil - ALiB. The extraction of lexical data follows a homogeneous methodological protocol that characterizes the ALiB corpus. It about the question number 001 of the Semantic-Lexical Questionnaire (QSL). The exploratory analysis comprises a total of 200 informants distributed in 25 Brazilian cities and based on a social stratification selection of informants (age, sex and education) proposed by ALiB Committee (2001). The results point to a productive variation in diatopics and diastratics terms. The item riacho/ córrego features 21 variants, the most productive are riacho, córrego and igarapé. The variant riacho is prevalent in the northeast, southeast (except Belo Horizonte) and south, while corrego prevails in the Midwest, and igarapé in northern Brazil. Social influence is more relevant for riacho and córrego lexical variants and appear more frequently in the responses of informants of the second age group, males, from higher education.

Keywords: Multidimensional Dialectology. Lexical Variation. 